\title{
Subsurface organic amendment with plastic film mulching reinforced soil organic carbon through altering saline soil aggregate structure and regulating fungal community
}

\author{
Hongyuan Zhang ${ }^{1}$, Huancheng Pang ${ }^{1}$, Jiashen Song ${ }^{1}$, Fangdi Chang ${ }^{1}$, Jing Wang ${ }^{1}$, Yitao \\ Zhang $^{2}$, and Li Yuyi ${ }^{1}$ \\ ${ }^{1}$ Chinese Academy of Agricultural Sciences Institute of Agricultural Resources and \\ Regional Planning \\ ${ }^{2}$ Institute of Geographic Sciences and Natural Resources Research Chinese Academy of \\ Sciences
}

January 3, 2022

\begin{abstract}
The combination of plastic film mulching and subsurface organic amendment is a novel strategy for saline soil amelioration and utilization in China. However, how the strategy affect soil organic carbon (SOC) contents directly and indirectly (physical protection and microbiological regulation) were still not-documented. Therefore, four treatments, i.e., no amendment with and without plastic film mulching, subsurface $(10-30 \mathrm{~cm}$ soil depth) organic amendment with and without plastic film mulching, were arranged and sampled after three-year filed experiment. Compared with no amendment with and without plastic film mulching, subsurface organic amendment increased the SOC content in the $0-40 \mathrm{~cm}$ soil depth by $70 \%$ and $90 \%$, respectively. Plastic film mulching decreased SOC by $16 \%$ without organic amendment. Subsurface organic amendment transformed the dominant aggregation particles from $<0.053 \mathrm{~mm}$ to $0.25-2 \mathrm{~mm}$, indicating that both direct carbon input and indirect physical protection contributed to SOC increment. Conversely, SOC decreased with plastic film mulching due to the $14 \%$ lower fungal diversity compared with soil without plastic film mulching, was supported by the positive path coefficient from fungal diversity to SOC. Therefore, the combination of plastic film mulching and subsurface organic amendment increased SOC by $61 \%$ by direct carbon input and indirect physical protection and microbial regulation. In conclusion, subsurface organic amendment with plastic film mulching reinforced soil organic carbon increment through altering saline soil aggregate structure and regulating fungal community, and confirmed it is a feasible way to increase SOC for saline soil amelioration.
\end{abstract}



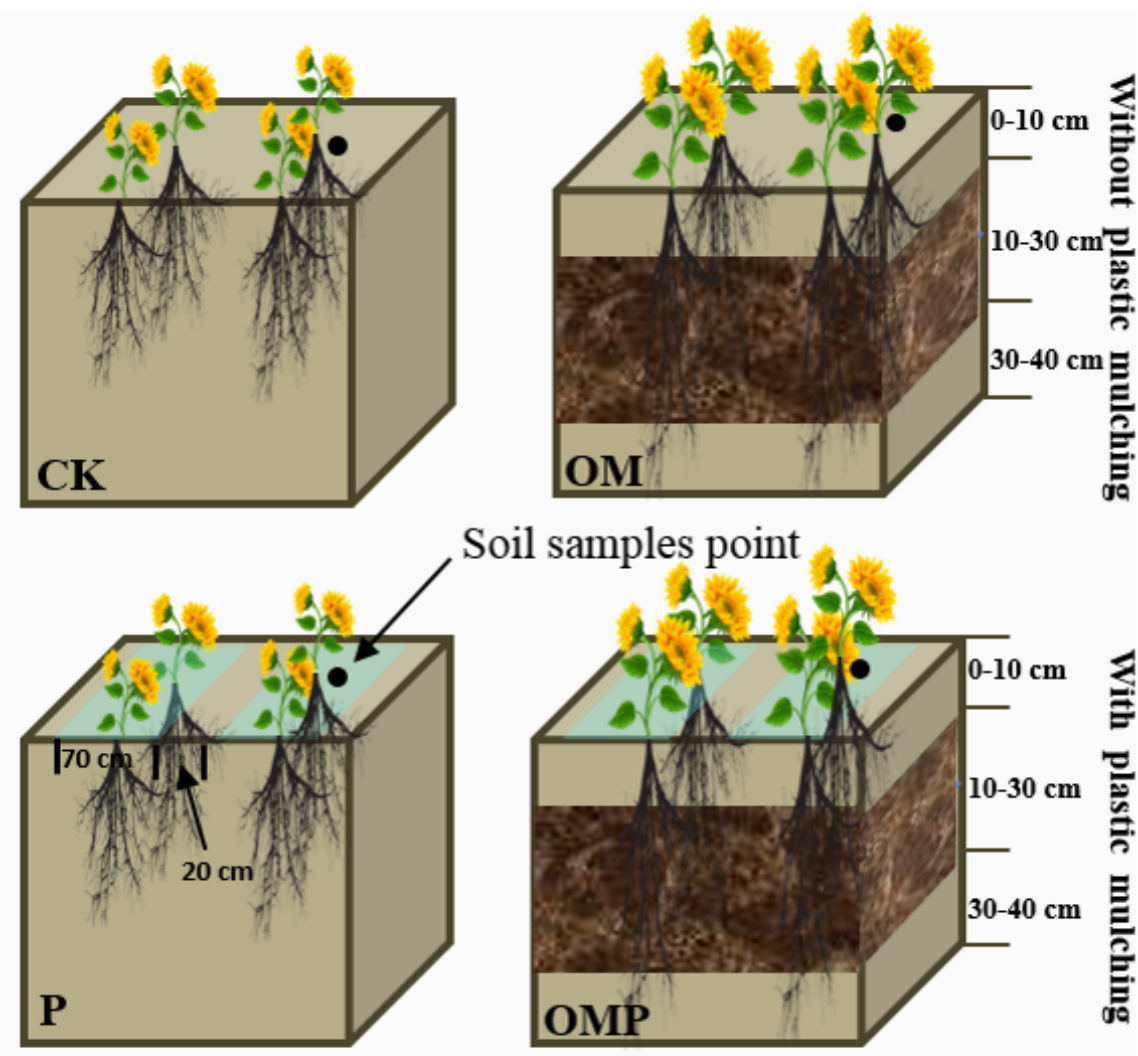

Subsurface amended without organic manure

Soil samples point

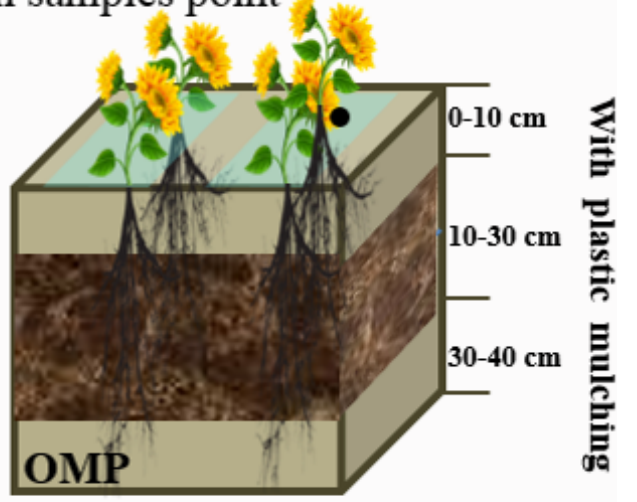

Subsurface amended

with organic manure

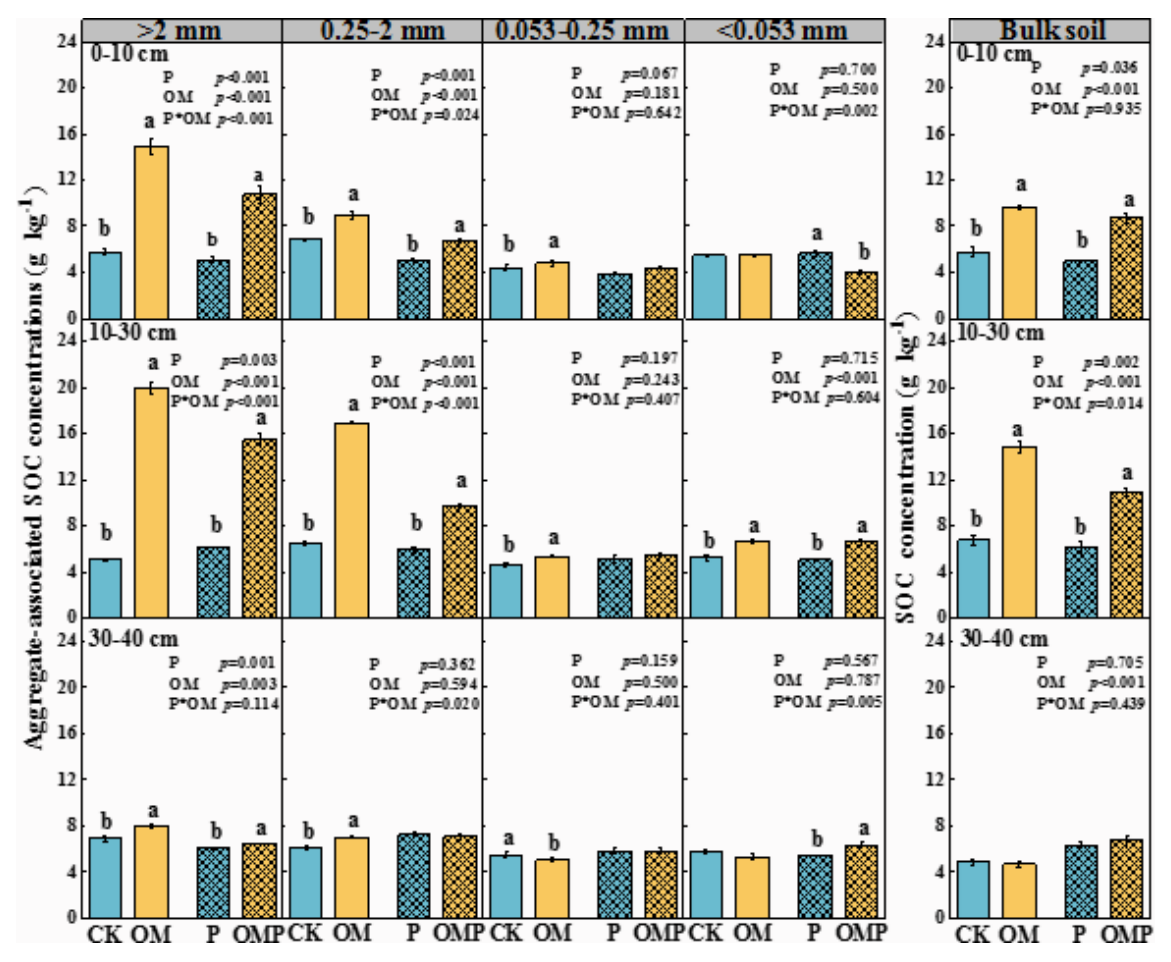



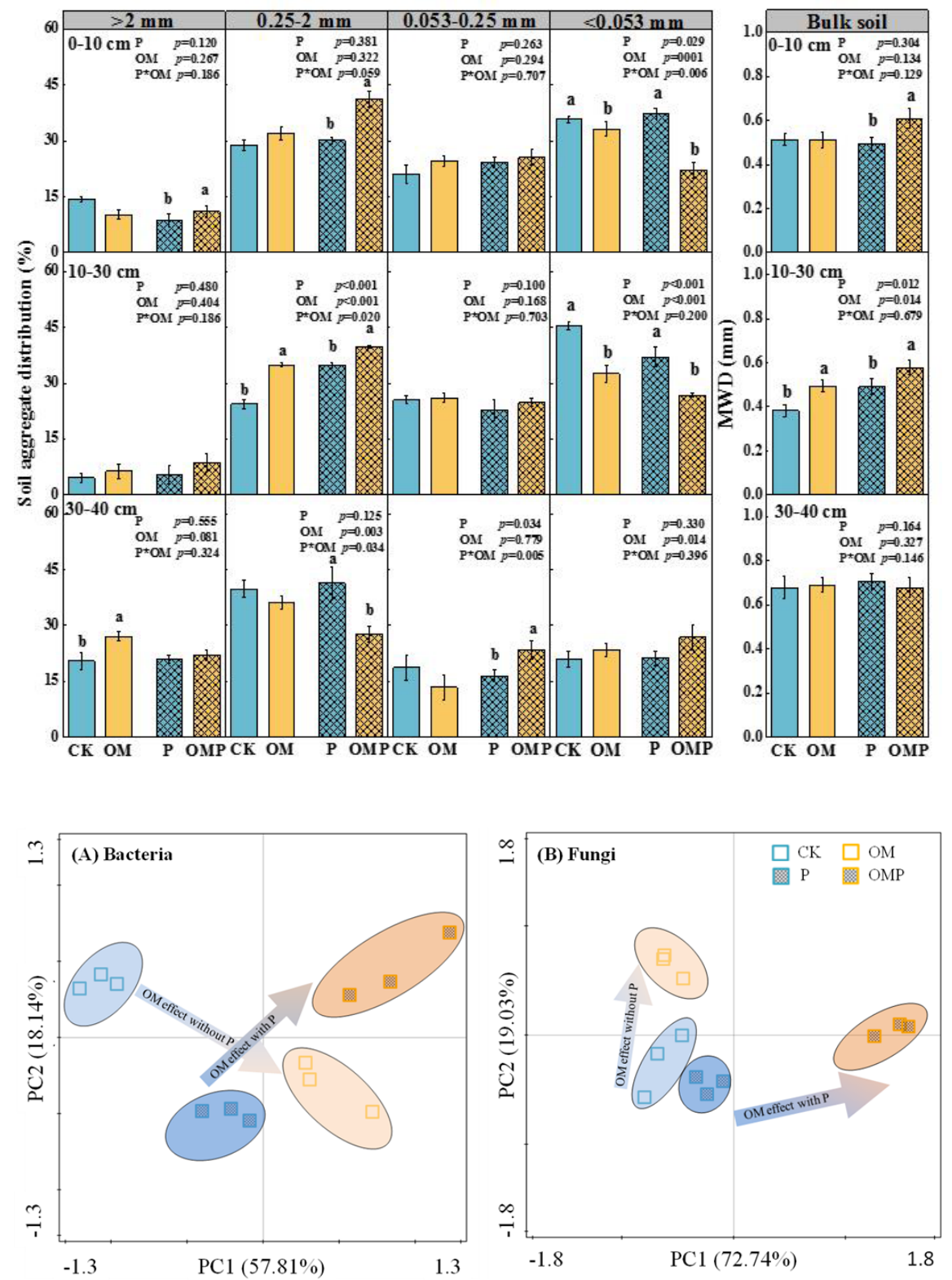
(A) Bacteria

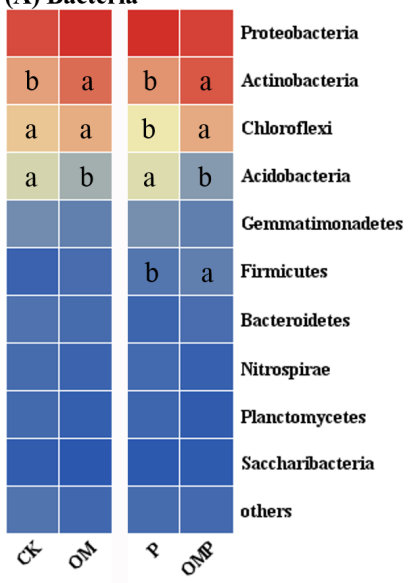

(B) Fungi

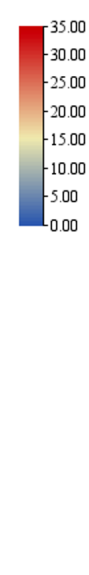

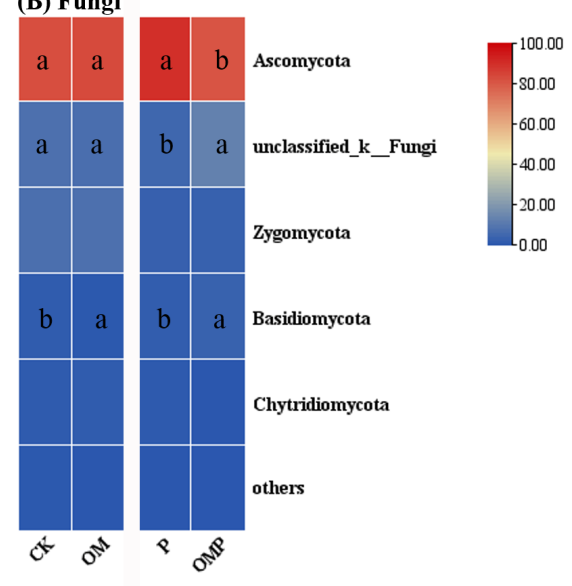

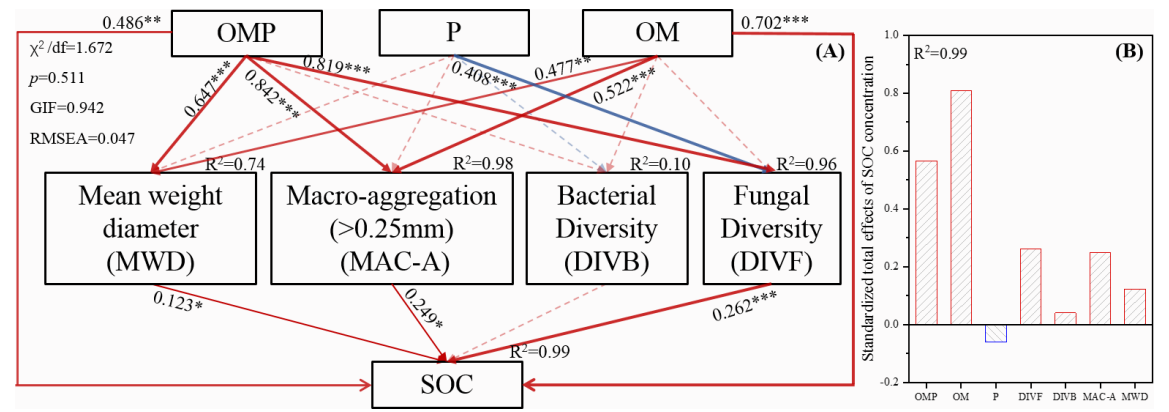

